\title{
Article \\ Evaluation of Changes in Structure of Modified Cement Composite Using Fractal Analysis
}

\author{
Grigory Yakovlev ${ }^{1}$, Irina Polyanskikh ${ }^{1}$, V. Belykh ${ }^{2}$, Vladimir Stepanov ${ }^{2}$ and Olga Smirnova ${ }^{3, * *(])}$ \\ 1 Department of Construction Materials, Mechanization and Geotechnics, Kalashnikov ISTU, 7, \\ Studencheskaya, 426069 Izhevsk, Russia; gyakov@istu.ru (G.Y.); irina_maeva@mail.ru (I.P.) \\ 2 Department of Physics and Optometry, Kalashnikov ISTU, 7, Studencheskaya, 426069 Izhevsk, Russia; \\ bil_ha@mail.ru (V.B.); vladimir1@udm.ru (V.S.) \\ 3 Department of Constructing Mining Enterprises and Underground Structures, Saint-Petersburg Mining \\ University, 21-st Line V.O., 2, 199106 Saint-Petersburg, Russia \\ * Correspondence: smirnovaolgam@rambler.ru
}

check for updates

Citation: Yakovlev, G.; Polyanskikh,

I.; Belykh, V.; Stepanov, V.; Smirnova,

O. Evaluation of Changes in Structure of Modified Cement Composite Using Fractal Analysis. Appl. Sci. 2021, 11, 4139. https://doi.org/ 10.3390/app11094139

Academic Editor: Dario De Domenico

Received: 18 March 2021

Accepted: 24 April 2021

Published: 30 April 2021

Publisher's Note: MDPI stays neutral with regard to jurisdictional claims in published maps and institutional affiliations.

Copyright: (c) 2021 by the authors. Licensee MDPI, Basel, Switzerland. This article is an open access article distributed under the terms and conditions of the Creative Commons Attribution (CC BY) license (https:/ / creativecommons.org/licenses/by/ $4.0 /)$

\begin{abstract}
The need for research using modern methods of physical and chemical analysis in combination with methods for processing the graphical results arises with an increase of developments aimed at changing the structure and properties of hydration-hardening materials. Currently, the method of scanning electron microscopy is widely used for the qualitative and quantitative analysis of materials. Additional information, including fractal analysis of the image, determines the information-entropy levels and the state of the information system in the form of the microstructure based on the generalized structural entropy that increases the volume and quality of analytical information extracted from the obtained images. Images with a magnification of 20,000 times were used to analyze the microstructure of a control cement composite and a carbon black modified composite. The fractal analysis of the images revealed a change in the relative organization of the system, which justifiedthe nature of the change in the physical and technical properties of the modified cement composite relative to the additive-free cement composite from the perspective of self-organization.
\end{abstract}

Keywords: soot nanoparticles; fractal analysis; modification; nano-structuring additives; self-organization

\section{Introduction}

Currently, a significant number of research and industrial developments have been accumulated on the introduction of nanotechnology in the production of building materials-in particular, the use of nano-structuring additives for composites based on hydrationhardening binders [1-3]. However, the number of studies attempting to determine the main factor that leads to significant changes in the composite structure is insufficient $[4,5]$ compared with the number of applied projects aimed at obtaining the optimal material compositions [6-9]. Over the past decade, research and testing has been carried out by the authors on the modification of cement and gypsum composites with aqueous suspensions of multilayer carbon nanotubes [10-13]. The nature of the effect of these additives allows confirmation of the non-additive nature of the effect of the active components of these additives. A number of studies have been performed to determine the leading role of additives in changing the characteristics of composites as a result of the complex impact of the various components. At the same time, it was proved that the separate addition of the components of a complex additive does not have such an effect on the final properties of the material $[4,14,15]$. The synergistic effect occurs due to the complex impact of the surface-active substance (superplasticizer) with carbon nanotubes on the structure of hardening composite $[10,11]$. However, modern methods of materials research do not allow the phenomenon of a synergistic effect to be proved by direct methods; mainly, the phenomenon is confirmed by a combination of a complex of indirect methods [16,17].

Systems of diverse nature are considered in synergetics as a complex of subsystems that perform certain technological functions. Subsystems are interconnected by processes 
of intensive dynamic interaction and exchange of energy, matter, and information [18-20]. Self-organization of dynamic systems is a complex mechanism of self-management in natural and artificial systems in which the corresponding properties of the systems are formed without external influence. The effects of self-organization in natural systems arise as a result of changes in the "control parameters", while the effects of self-organization in artificial systems are formed as a result of the construction of feedback. Knowledge of the laws of the behavior of synergetic systems allows one to think deeply about the creation of artificial systems in which the processes of purposeful self-organization form the desired structures [21-23].

Materials based on hydration binders that are modified with amulticomponent additive containing carbon nanotubes can serve as an example of artificial systems capable of self-directed organization. To date, the optimal ratios of components in anadditive composition have been stated, leading to a significant enhancementof the physical and mechanical characteristics of matrices based on hydration-hardening binders [24-26]. At the same time, significant changes in structure of the material are noted by many researchers [27-29].

The complex of modern methods of physical and chemical studies indirectly allows stating the causes and mechanisms that justify a significant improvement of composite properties [30-33]. Studies of physical and mechanical properties confirm the non-additive nature of the effect of multicomponent additives [34-36]. Modern physical and chemical studies including scanning electron microscopy with X-ray microanalysis, $\mathrm{X}$-ray phase analysis, IR spectral analysis, computed tomography, and differential thermal analysis are able to determine the changes occurring in the composite material at the level at which hydration products are formed [37-39]. However, the information extracted from the analysis of the material microstructure is often used by researchers only to determine the morphology and size of hydration products [40,41]. This does not allow full use of the information of the bitmap image [42-44].

The determinationof links among the elements of system andthe causality of movement of each element when interacting with other elements is the main property of information. The existence of a certain relationship between the production of entropy in the system and the exchange of entropy with the external environment is a prerequisite for structure formation in open systems. The effect of information, in contrast to entropy, is expressed in a tendency to increase orderliness and reduce uncertainty. Currently, the concept of entropy as a fundamental physical quantity is expanding and deepening in connection with the ability to evaluate information through its analysis. The analysis of the entropy characteristics of amicrostructure of concrete and mortar allows evaluation ofthe changes in itsintegral characteristics, such as the electrical resistance and the configuration entropy of the structural elements. However, physical entropy and information entropy may not coincide, and therefore it is necessary to introduce abstract concepts such as "entropy force", "information capacity", and"information potential" in order to remain within the framework of thermodynamic concepts when working with information.

Information transformations are the basis for thefractal analysis of structures of various natures. On this basis, the methods and computer programs for multifractal parametrization of flat images have been developed to solve problems for optimizing the fractal structures of a material in technological processes [45-47] as well as to study their stability and adaptive properties [48-50].

There is research showing that fractal analysis is used to study the structure of materials for construction purposes [51-53]. Thus, onpaper [54], the statistical and geometric characteristics of microstructure of the pore space of rock samples were studied on the basis of a3D micromodel. In the study [55], the variability (statistical stability) of the fractal characteristics (fractal dimension $\mathrm{D}$ and lacunarity $\Lambda$ of the microstructure) from the action of various nanomodifiers was evaluated using the example of nano-structured concrete. It was stated that the value of the fractal dimension was more invariant when introducing the modifiers than the lacunarity. It was noted that the lacunarity significantly depends on the magnification at which the microstructure was obtained. 
Analyzing the studies in this area, it can be concluded that fractal analysis is almost not used to assess the degree of self-organization of hardening cement systems. Thus, the aim of our research was to evaluate the changes in the structure of the modified cement composite using fractal analysis.

\section{Materials and Methods}

\subsection{Samples Preparation}

Sample-beams with dimensions of $4 \times 4 \times 16 \mathrm{~cm}$ were made to study the features of composite structure formation. Ordinary Portland cement of CEM I $42.5 \mathrm{~N}$ strength class was used as a binder. The chemical and mineral composition of cement wasrepresented by the following minerals as a percentage: tricalcium silicate $\mathrm{C}_{3} \mathrm{~S}-64.6$, bicalcium silicate $\mathrm{C}_{2} \mathrm{~S}-10.7$, tricalcium aluminate $\mathrm{C}_{3} \mathrm{~A}-7.0$, and tricalciumaluminoferrite $\mathrm{C}_{4} \mathrm{AF}-14.7, \mathrm{MgO}-1.4$.

Cement-sand mortars (mortar modified with an additive and the control mortar) were made to determine theirmechanical characteristics. Soot was used as a modifying additive. It acted as a control parameter for changing the functional quality of the information system of the mortar microstructure. Soot with aparticle size less than $80 \mathrm{~nm}$ and with aspecific surface area of $65-100 \mathrm{~m}^{2} / \mathrm{g}$ was used. The amount of carbon black used to modify the samples was dosed as a percentage of the binder weight. A change in the configuration entropy of the system is expected when using technical soot as a modifier.

The water-to-binder ratio was 0.52 for all compositions. The samples were stored in wet conditions for 28 days prior to the test.

\subsection{Testing of Samples}

Tests for determiningthe tensile strength in bending and compressive strength of samples were carried out using aPGM-100 MG4-A hydraulic press with amaximum load of $100 \mathrm{kN}$ and a loading speed of $0.5 \mathrm{MPa} / \mathrm{s}$. Samples of control and modified compositions were selected for microstructure study. Preliminary deposition of a gold-based conductive film was applied to samples. The scanning electron micrographs were obtained using aMIRA 3 TUSCAN microscope at the AdMaS Research Center located at the Technical University of Brno. A statistically significant number of images were taken in the study, and the most characteristic results were analyzed and are presented. Differential thermogravimetry (DTG) and differential scanning calorimetry (DSC) methods were used. Laboratory studies were conducted on a TGA/DSC1 thermal analyzer produced by Mettler-Toledo Vostok. Shooting conditions: measurement interval $50-1100{ }^{\circ} \mathrm{C}$, heating rate $10 \mathrm{deg} / \mathrm{min}$, platinum crucibles, working medium-air. Obtained results were discussed in previously published data [56].

\subsection{Calculation of Multifractal Parameters}

Multifractal analysis of concrete surface images was carried out in accordance with the methodology described in papers $[9,10]$ and includedthe following steps:

- Obtaining the digital image of the concrete surface under study using an electron microscope according to the scheme in Figure 1;

- Selecting the sections of scanner images of the microstructure of concrete samples;

- Calculating the multifractal characteristics for the scanning area;

- $\quad$ Studying the obtained multifractal characteristics.

\begin{tabular}{|c|c|}
\hline $\mathrm{AA}$ & $\mathrm{AB}$ \\
\hline $\mathrm{BA}$ & $\mathrm{BB}$ \\
\hline
\end{tabular}

Figure 1. Scheme for selecting the image scan areas.

The calculation of the multifractal parameters was performed on the basis of parametrization of electron microscopic images of microstructures using a computer program [57]. For this purpose, an equallycellular square partition of the studied image 
structure wasused. A measure in the form of a positive number was mapped to each cell. It characterized the area of the structure in thecell.

The processing principle wasas follows. Images of fractal objects weredivided into square cells with aside $\delta$ that variedfrom 3 to 50 pixels, digitizing the image size of $r \times c$, where $r$ is the number of rows and $c$ is the number of columns. The minimum cell is the pixel of the image $x_{i j}, i=\overline{1, r}$ and $j=\overline{1, c}$, which characterizes the grayscale from 0 to 255, where 0 means black and 255 means white. The technique of multifractal parametrization of the image is known and it uses the calculation of moments $p_{k}^{q}$-the probability of distribution of points of the set in the cells [46,54]; the developed program provides the choice of the gray scale interval when digitizing the image. The number of single pixels is calculated in each "non-empty" cell by formula:

$$
M_{k}=\sum_{i=r(k)}^{r(k)+\delta-1} \sum_{j=c(k)}^{c(k)+\delta-1} y_{i j}(\Gamma), k=\overline{1, N(\delta)}
$$

where $r(k)$ and $c(k)$ are, respectively, the number of the row and column of the pixel with which the $k$-th cell begins.

The number of single pixels of the image is calculated by the formula:

$$
M=\sum_{k=1}^{N(\delta)} M_{k}
$$

The "population" of the $k$-th cell can be determined:

$$
p_{k}=\frac{M_{k}}{M}, k=\overline{1, N(\delta)}
$$

The normalization condition must be met:

$$
\sum_{k=1}^{N(\delta)} p_{k}=\sum_{k=1}^{N(\delta)} \frac{M_{k}}{M}=1
$$

The moment $p_{k}^{q}$-th order determines the value of $D_{q}$, which corresponds to the degree of sparsity of the multifractal multitude:

$$
\mathrm{Z}(q, \delta)=\sum_{k=1}^{N(\delta)} p_{k}^{q}
$$

where $q \in(-\infty, \infty)$. In the literature, the minimum and maximum sparsity are limited to the consideration of $\mathrm{D}_{+40}$ and $\mathrm{D}_{-40}$.

For integer values $q(-40,-39, \ldots, 39,40)$ the discrete values $D_{q, \delta}$ depending on the cell size of $\delta$ are:

$$
D_{q, \delta}=\left\{\begin{array}{c}
\frac{\ln \sum_{k=1}^{N(\delta)} p_{k}^{q}(\delta)}{(1-q) \ln \delta}, \quad q \neq 1 \\
\frac{\ln \left(\sum_{k=1}^{N(\delta)} p_{k}(\delta) \cdot \ln p_{k}(\delta)\right)}{\ln \delta}, \quad q=1
\end{array}\right.
$$

The proposed method differs from the binary image because the image is analyzed for the grayscale interval (the optical density region can be set arbitrarily).

The multifractal parametrization of the material structure image describes its statistical properties by the spectrum of generalized dimensions of Renee of $D_{q}$. For $q=1$, we get the information dimension of $D_{1}$ (the Shannon index). The value of $K_{s}=D_{1}-D_{40}$ is used as an order measure. The quantitative measure of chaos in the system under study is taken as $\Delta D=D_{-40}-D_{+40}$. 
The states of static stability of the structure, the so-called maxima of the information dimension, are stated from the graph of dependence of the information dimension of $D_{1}$ on the scale of $d$ of structure elements. States with the maximum value of the information dimension of $D_{1 i}=$ const can be considered as a memory matrix written as the static stability of the active elements of structure, where $D_{1 i}$ is the information dimension of the $i$-th level. The generalized information entropy is equal to the sum of the information dimensions of the stationary levels of $H=\sum D_{1 i}$, and it characterizes the static state of the structural entropy.

Information transformations of the image are accompanied by configuration changes of the active elements of structure, causing the increase of the measure of $\Delta D$ randomness. The states of the dynamic stability of structure-namely, the maxima of $\Delta D^{*}$ and the information dimension of $D 1^{*}$-are stated from the graph of dependence of $\Delta D$ on the scale of $d$ of the structure elements. The information entropy of $H^{*}=\sum D^{*}{ }_{1 i}$ characterizes the dynamic state of the structural entropy, where $D^{*}{ }_{1 i}$ is the information dimension of the $i$-th level of randomness.

An increase of the system complexity occurs due to an increase of the number of heterogeneous elements and connections between them, creating the $N$ stable stationary states with the set of probabilities of $p_{1}, p_{2}, \ldots, p_{N}$. The amount of information corresponding to this state of the system is expressed by the K.Shannon's formula $H=-\sum^{N}{ }_{j} P_{j} \log _{2} P_{j}$. The number of $N$ determines the information capacity-namely, the maximum amount of information of $H_{\text {max }}$ that the system contains-and it is determined under the equally probable condition of $P=1 / N$. The maximum structural entropy of the information system of $H_{\text {max }}=-\log _{2} P=\log _{2} N$ corresponds to the equilibrium state of physical chaos in the system, and it is measured in bits.

The difference of $H_{\max }-H^{*}$ and $R=1-H^{*} / H_{\max }$ express the absolute and relative organization of the system. Relative randomness of the system is $S=H^{*} / H_{\max }$. The structural entropy of the dynamic state of the information system as $H^{*}=H_{\text {max }}$ corresponds to the state of physical chaos, and the loss of the functional quality of structure, herewith the relative organization, is $\mathrm{R}=0$.

\section{Results and Discussion}

Studies of physical and mechanical properties of the control (additive-free) and modified compositions show that the compressive strength of the control sample was $20.8 \mathrm{MPa}$, and the tensile strength in bending was $4.26 \mathrm{MPa}$. The compressive strength of the modified sample with $0.02 \%$ of soot was $26.9 \mathrm{MPa}$; the tensile strength in bending was $5.2 \mathrm{MPa}$.

The results of $X$-ray phase analysis and differential thermal analysis show that the number of changes in the composition of the modified sample wasinsignificant, despite a significant increase of its strength characteristics. It can be assumed that the effect of the additive on the conditions of structure formation does not change the composition of hydration products. The phenomenon of the synergistic effect is an example of nonlinear phenomena; in the analysis of the synergistic effect, forecasting is primary, since the variance of the results becomes comparable with the mathematical expectation, which affects the requirement for the accuracy of the results.

The results of scanning electron microscopy show changes in the shape and size of the structural elements (Figure 2). 


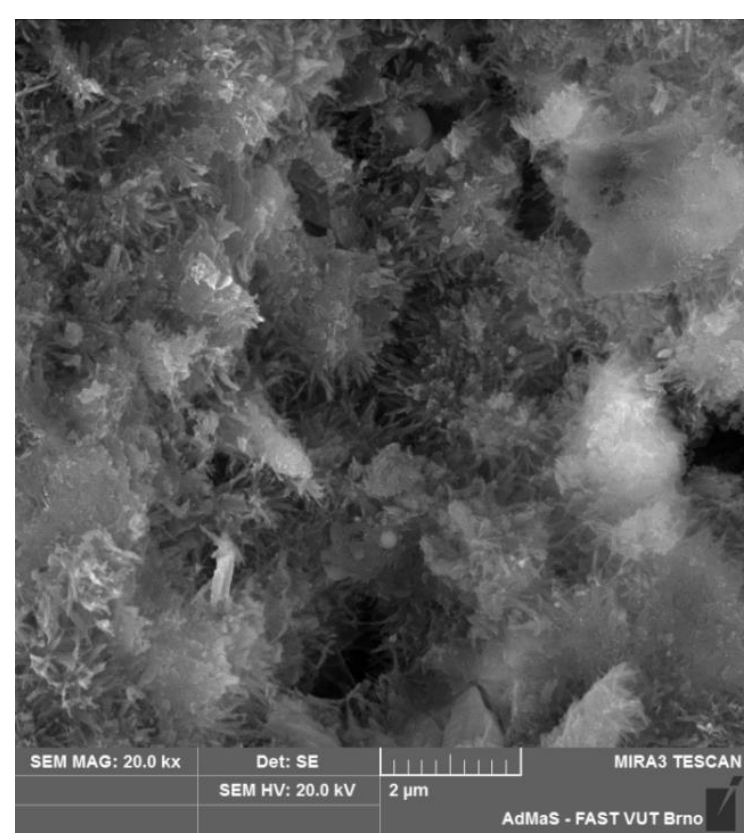

(a)

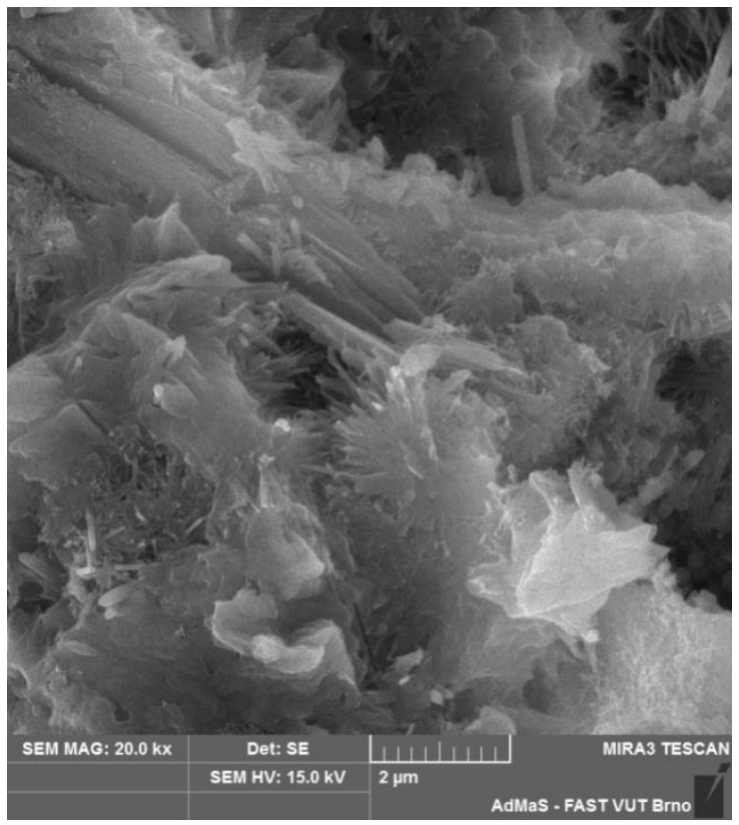

(b)

Figure 2. Microstructure of samples at magnification of 20,000: (a) control sample; (b) sample with $0.02 \%$ of soot.

Morphological differences in structure, differences in phase and chemical composition, and local differences in physical and mechanical properties by volume were observed in the cement matrix. Modification of matrices of hydraulic and non-hydraulic binders by dispersed additives also ledto significant changes in the morphology of the hydration products [10-12].The transformations of substances and the transformation of energy occurredin separate elementary volumes, which were interconnected by the diffusion transfer of atoms and energy. This supports the non-equilibrium state of the open system and the processes of self-organization accompanied by changes in the thermodynamic variables of the system.

The concrete structure was heterogeneous due to the technological features and features of the structure formation. The concrete structure was characterized by a chaotic distribution of defects. Hardening was characterized by simultaneous ordering processes-the crystal grewover time and degradation processes-the formation and change of the pore space that ledto a non-equilibrium state of the system.

Thus, the influence of additives on the early hydration of the hardening cement matrix that ledto the increase of thermodynamic fluctuations of hereditary disorder in a chaotic system wasone of the possible mechanisms of the influence of additives on the processes of structure formation. Hence, it was possible to manifest the self-organization by acquiring its own nonlinear dynamics, which reducedthe structural entropy and increasedthe adaptation. The order processed and formed local regions with short-range order developing as a structuring information principle long before the appearance of the center of formation of a new phase, as a process of production and materialization of information in the form of a specific topological scheme (nature, shape, size of additive particles, and their aggregation into clusters with strong associative connections).

The results of the multifractal analysis of the electron microscopic image of microstructure of the control sample are shown in Figure 3. The entropy parameters of the static and dynamic stabilities of the microstructure are given in Table 1. 

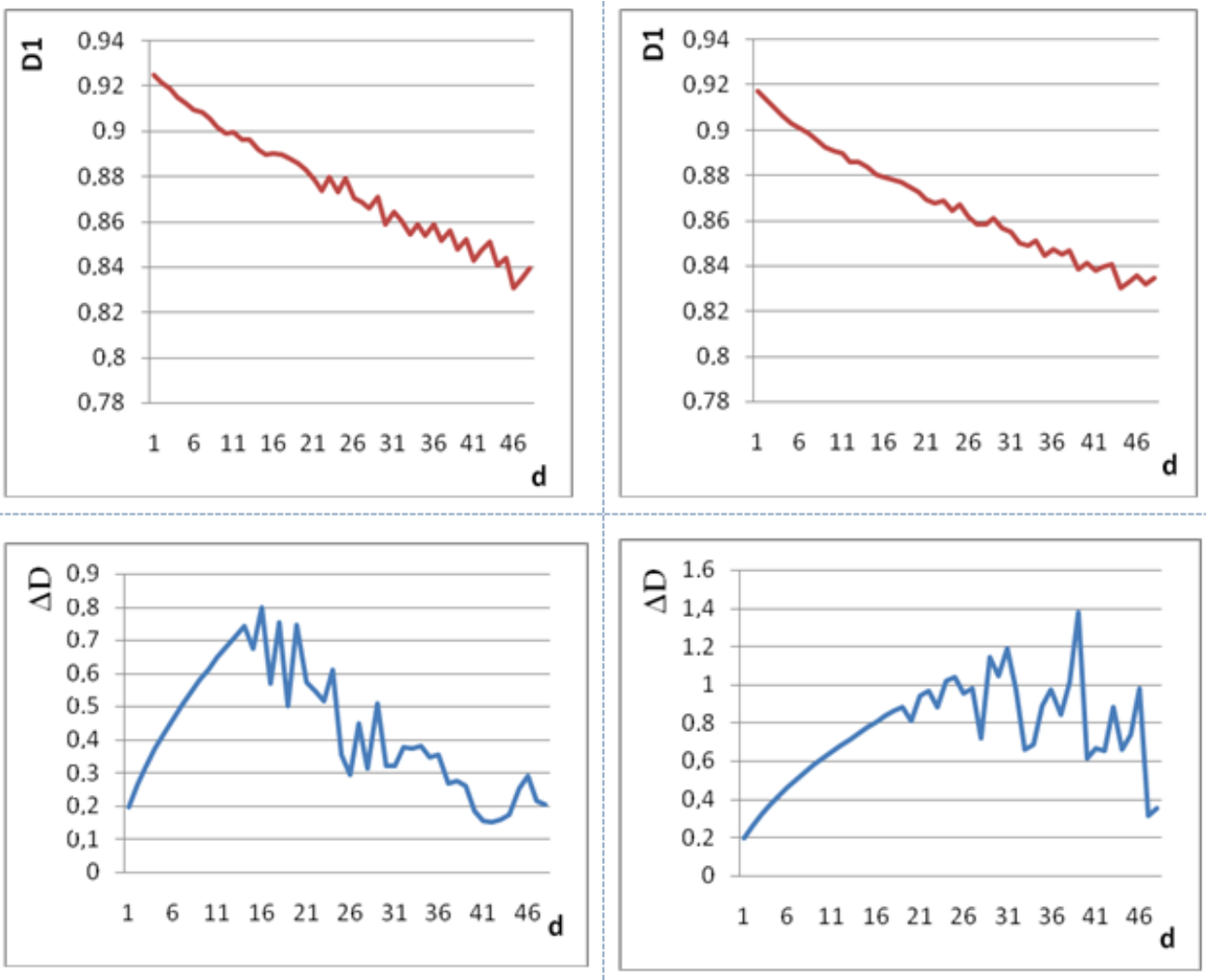

\section{AABA}

Figure 3. Results of the multifractal analysis of the electron microscopic image of control sample structure: the effect of the $d$ scale on the information entropy of $D 1$ and $\Delta D$.

Table 1. Entropy parameters of the control additive-free sample.

\begin{tabular}{|c|c|c|c|c|}
\hline Microstructure & AA & $\mathrm{AB}$ & BA & BB \\
\hline Status Function & Deterministic & Deterministic & Deterministic & Deterministic \\
\hline $\mathrm{H}$ & 13.07 & 10.22 & 10.3 & 10.33 \\
\hline $\mathrm{H}_{\max }$ & 18.92 & 14.8 & 14.91 & 14.95 \\
\hline $\mathrm{H}^{*}$ & 10.43 & 8.49 & 10.22 & 8.52 \\
\hline $\mathrm{S}=\mathrm{H}^{*} / \mathrm{H}_{\max }$ & 0.55 & 0.57 & 0.69 & 0.57 \\
\hline$\Delta \mathrm{H}=\mathrm{H}_{\max }-\mathrm{H}^{*}$ & 8.49 & 6.31 & 4.69 & 6.43 \\
\hline $\mathrm{R}=1-\mathrm{S}$ & 0.45 & 0.43 & 0.31 & 0.43 \\
\hline $\begin{array}{l}\text { Transmitted information } \\
\mathrm{H}_{\mathrm{old}} / \mathrm{H}^{*}\end{array}$ & 0.42 & 0.3 & 0.5 & 0.3 \\
\hline $\begin{array}{l}\text { New information } \\
\mathrm{H}_{\text {new }} / \mathrm{H}^{*}\end{array}$ & 0.58 & 0.7 & 0.5 & 0.7 \\
\hline $\mathrm{H}-\mathrm{H}^{*}$ & 2.64 & 1.73 & 0.08 & 1.81 \\
\hline $\mathrm{D}_{\text {lequil }}$ & 0.89209 & 0.87534 & 0.8753 & 0.8805 \\
\hline $\mathrm{D}_{\text {1non-equil }}$ & 0.83098 & 0.83175 & 0.83473 & 0.83609 \\
\hline $\mathrm{K}=\exp (\mathrm{H})$ & $4.7 \times 10^{5}$ & $2.7 \times 10^{4}$ & $2.94 \times 10^{4}$ & $3.1 \times 10^{4}$ \\
\hline $\mathrm{K}^{*}=\exp \left(\mathrm{H}^{*}\right)$ & $3.4 \times 10^{4}$ & $0.5 \times 10^{4}$ & $2.7 \times 10^{4}$ & $0.5 \times 10^{4}$ \\
\hline
\end{tabular}


The deterministic function of the information system of the image of the control sample microstructures has the relative randomness $\mathrm{S}=0.55-0.69$ and the relative organization $\mathrm{R}=0.31-0.45$. One can note the value of $70 \%$ of the renewal of active elements of the microstructure in the spectrum of levels of the dynamic state of microstructures of the $\mathrm{AB}$ and $\mathrm{BB}$ cells. The entropy of the equilibrium levels of the $\mathrm{AB}$ and $\mathrm{BB}$ cells is $\mathrm{D} 1_{\mathrm{eq}}=0.87534$ and $\mathrm{D} 1_{\mathrm{eq}}=0.8805$, respectively. For the BA cell (Table 1 ), the update is $50 \%$, and the structural entropies of the static and dynamic states are close in magnitude. The invariant variety is observed in the change $\Delta \mathrm{D}$ (Figure 3) in the form of increasing the resonant maxima in a wide range of changes in the scale of $d$. The relative organization of the functional state of the information system of the BA microstructure is $\mathrm{R}=0.31$. The structural entropy of the static state exceeds the entropy of the dynamic state in the information system of the AA microstructure, so the information capacity of $K=\exp (H)=$ $4.7 \times 10^{5}$ is higher than the capacity of $K^{*}=\exp \left(H^{*}\right)=3.4 \times 10^{4}$.

The high potential of choice (information capacity) of the static state forms a gradient force of influence on the dynamic state, probably providing the increase of the relative organization of $\mathrm{R}=0.45$ of the microstructure of the AA cell. A single information maximum is observed in the near-order change of $\Delta \mathrm{D}$ in the scale change interval of $d$. It can be assumed that the development of the crystal intergrowth is provided due to the high potential of choice (information capacity) of the static state of the information system. This confirms the nonequilibrium of states due to the presence of gradient-phase components in the microstructure of the control sample.

The results for determining the entropy parameters of structure of the control additivefree sample are presented in Table 1 , where $\mathrm{H}$ is the general structural information entropy, $H_{\max }$ is the maximum information, $H^{*}$ is the configuration entropy, $R$ is the value of relative organization of the system, D1equil is the value of the information dimension, $K$ is the information capacity, and $\Delta D$ is the measure of randomness.

The results of the multifractal analysis of the electron microscopic image of the microstructure of the modified sample are shown in Figure 4. The entropy parameters of the static and dynamic stability of microstructure are given in Table 2.
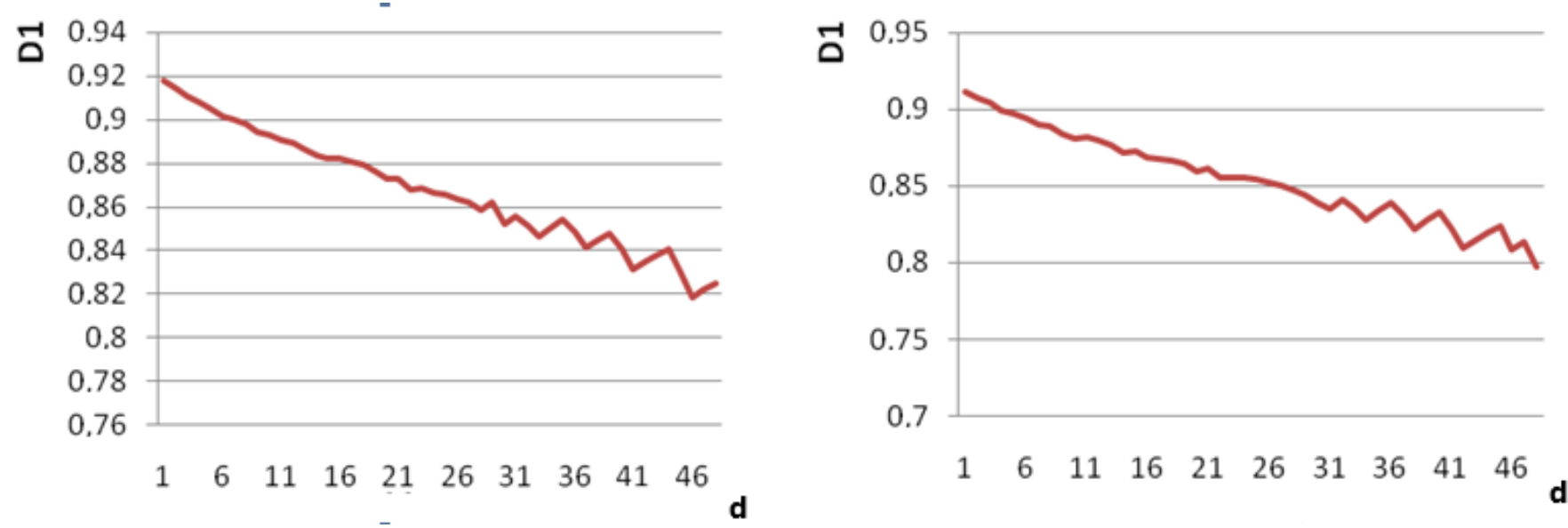

Figure 4. Cont. 

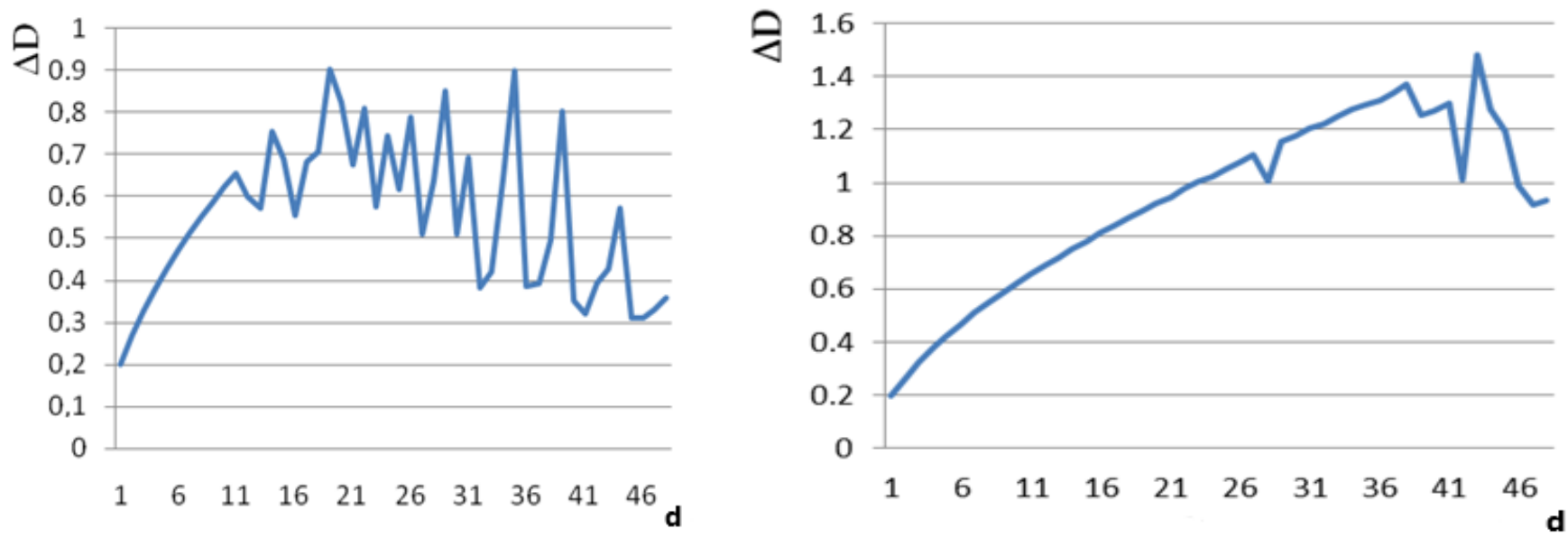

AABA

Figure 4. Results of the multifractal analysis of electron microscopic image of the modified sample microstructure: the effect of the $d$ scale on the information entropy of $D 1$ and $\Delta D$.

Table 2. Entropy parameters of the modified sample microstructure.

\begin{tabular}{|c|c|c|c|c|}
\hline Microstructure & AA & $\mathbf{A B}$ & BA & BB \\
\hline Status Function & Stochastic & Deterministic & Deterministic & Deterministic \\
\hline $\mathrm{H}$ & 6.89 & 9.53 & 8.537 & 10.11 \\
\hline $\mathrm{H}_{\max }$ & 9.97 & 13.8 & 12.36 & 14.64 \\
\hline $\mathrm{H}^{*}$ & 10.73 & 8.72 & 4.11 & 7.74 \\
\hline $\mathrm{S}=\mathrm{H}^{*} / \mathrm{H}_{\max }$ & 1.08 & 0.63 & 0.33 & 0.53 \\
\hline$\Delta \mathrm{H}=\mathrm{H}_{\max }-\mathrm{H}^{*}$ & -0.757 & 5.08 & 8.25 & 6.9 \\
\hline $\mathrm{R}=1-\mathrm{S}$ & -0.08 & 0.37 & 0.67 & 0.47 \\
\hline $\begin{array}{l}\text { Transmitted information } \\
\mathrm{H}_{\mathrm{old}} / \mathrm{H}^{*}\end{array}$ & 0.39 & 0.1 & 0 & 0.21 \\
\hline $\begin{array}{l}\text { New } \\
\text { Information } \mathrm{H}_{\text {new }} / \mathrm{H}^{*}\end{array}$ & 0.61 & 0.9 & 1.0 & 0.79 \\
\hline $\mathrm{H}-\mathrm{H}^{*}$ & -3.34 & 0.83 & 4.43 & 2.37 \\
\hline $\mathrm{D}_{1 \text { equil }}$ & 0.89085 & 0.907 & 0.8502 & 0.85076 \\
\hline $\mathrm{D}_{1 \text { non-equil }}$ & 0.82523 & 0.8416 & 0.7976 & 0.80827 \\
\hline $\mathrm{K}=\exp (\mathrm{H})$ & $9.82 \times 10^{2}$ & $1.4 \times 10^{4}$ & $5.1 \times 10^{3}$ & $2.4 \times 10^{4}$ \\
\hline $\mathrm{K}^{*}=\exp \left(\mathrm{H}^{*}\right)$ & $2.1 \times 10^{4}$ & $6.1 \times 10^{3}$ & 60 & $2.3 \times 10^{3}$ \\
\hline
\end{tabular}

The functional state of the microstructure of the modified sample is determined by the deterministic and stochastic functions of the information system.

Parameters of the deterministic function:

(1) Equilibrium level: $D_{1 \max }=0.851-0.97$; orderliness $K_{s}=5.2-31.6 \times 10^{-3}$; scale of structure elements $d=10-29$ pixels; relative orderliness $R=0.931-0.94$.

(2) Non-equilibrium level: $D_{1 \min }=0.798-0.842$; orderliness $K_{s}=7.4-45 \times 10^{-3}$; scale of structure elements $d=49-50$ pixels; relative orderliness $R=0.37-0.67$.

Parameters of the stochastic function:

(1) Equilibrium level: $D_{1 \text { max }}=0.8909$; orderliness $K_{s}=16.37 \times 10^{-3}$; scale of structure elements $d=13$ pixels; relative orderliness $R=0.91$.

(2) Non-equilibrium level: $D_{1 \text { min }}=0.8253$; orderliness $K_{s}=29 \times 10^{-3}$; scale of structure elements $d=50$ pixels; relative orderliness $R=-0.08$. 
The spectrum of information-entropy levels of dynamic deterministic states of the information systems of the control sample for the BB section and the modified sample for the AA section areshown in Figure 4. The influence of the scale on the changes in the information entropy of $D_{1}$ and the ordering of $K_{S} \times 10^{-3}$ in the spectrum of levels of dynamic state of the information system of the modified and control microstructures are analyzed in Figures 5-7.

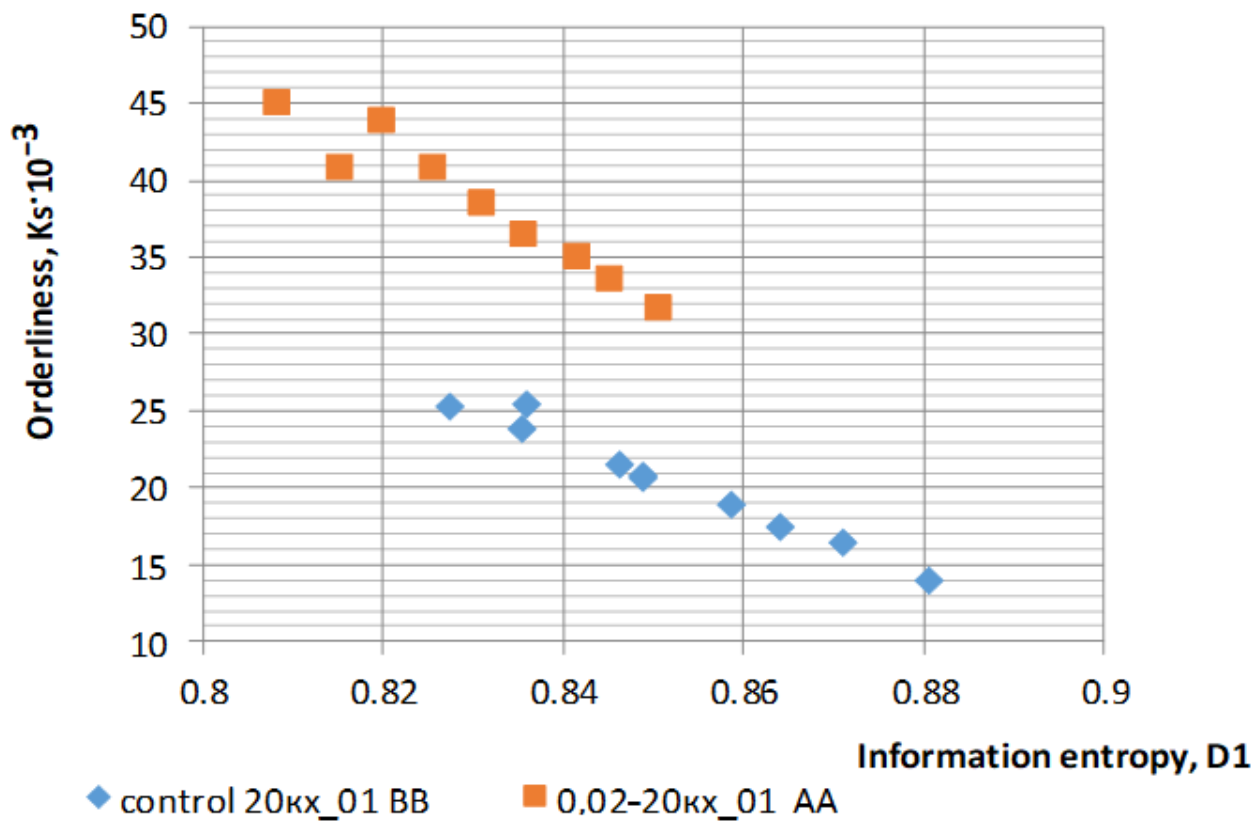

Figure 5. Dependence between the orderliness of $K_{S} \times 10^{-3}$ and the information entropy of $D_{1}$ in the spectrum of levels of the dynamic deterministic state of the information system.

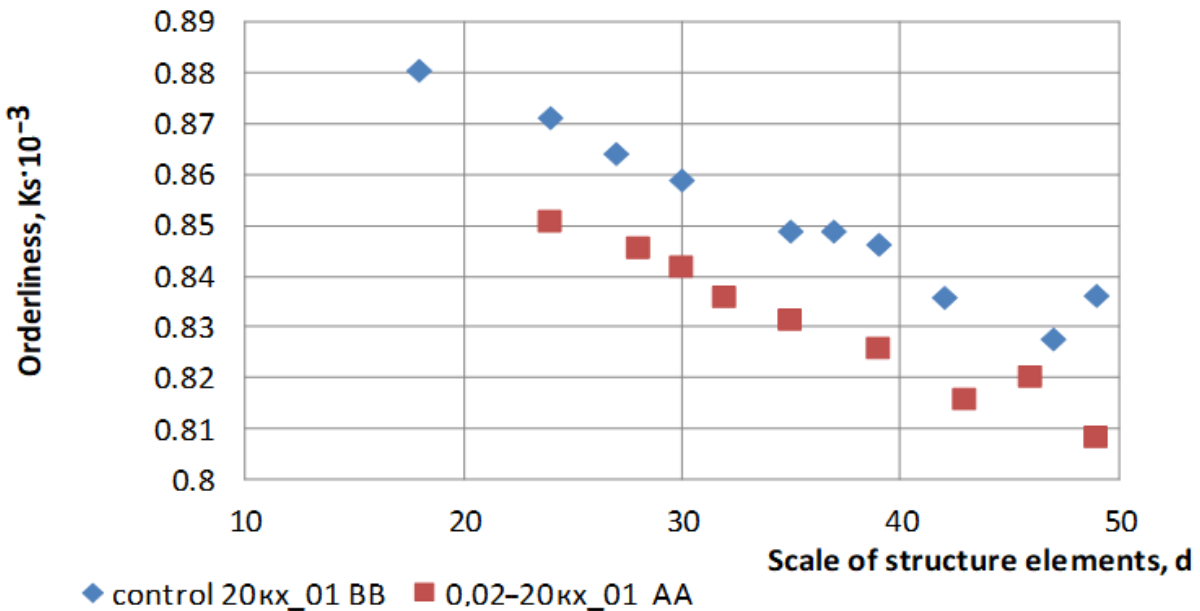

Figure 6. The effect of the $d$ scale on change in the information entropy of $D_{1}$ in the spectrum of levels of dynamic state of the information system of modified and control microstructures. 


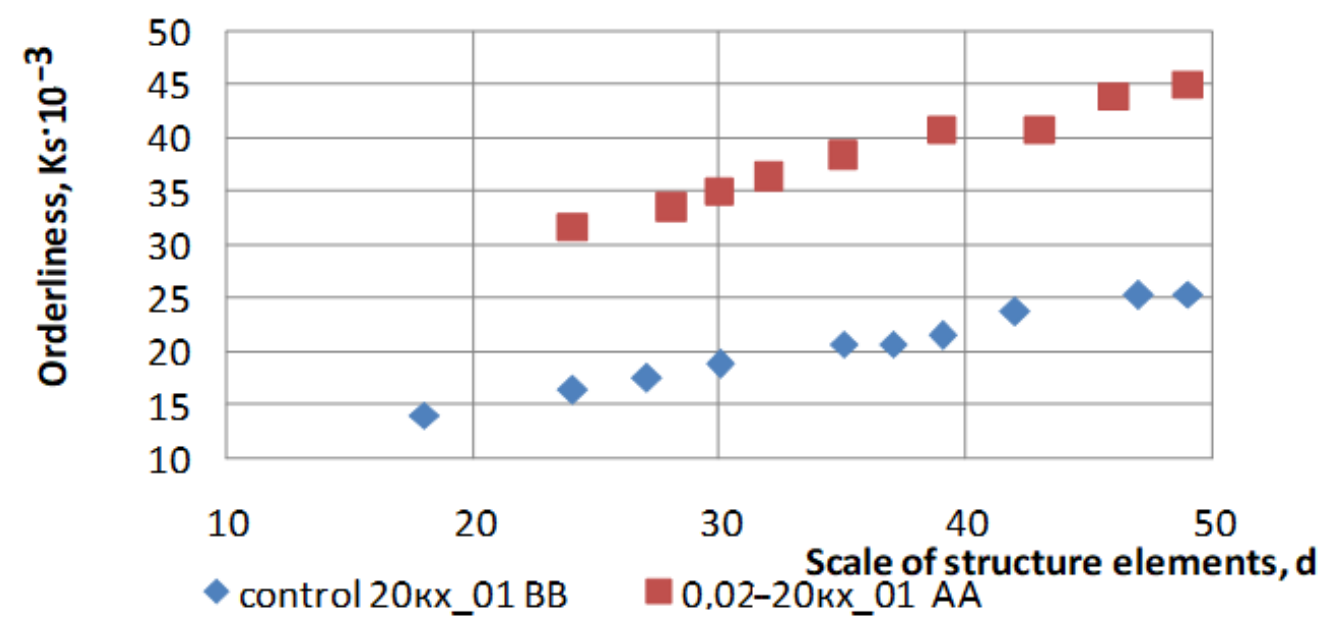

Figure 7. The effect of the $d$ scale on change of the orderliness of $K_{S} \times 10^{-3}$ in the spectrum of levels of dynamic state of the information system of modified and control microstructures.

The analysis of the spectrum of information-entropy levels of the dynamic state of the information system of the microstructures of control and modified samples (Figures 5 and 6) shows an increase of the information entropy of $D_{1 i}$ and a decrease of the orderliness of $K_{S}$ levels with a scale change (the increase of the cell size of $d$ ).

It should be noted that the modification of cement composite increases the thermodynamic fluctuations of chemical and phase compositions, affectsthe parameters of $K_{s}$ orderliness and the entropy of $\mathrm{D}_{1}$ in the information system of microstructure, and leads to disorder both of the scale invariance and the monotony of dependencies. The break points of the dependencies correspond to non-equilibrium phase transitions. The modification is accompanied by the increase of the orderliness of $K_{s} \times 10^{-3}$ and the decrease of the information entropy in spectrum of dynamic deterministic state of the composition, with the additive due to the processes of dynamic self-organization in the course of information transformations. The processes of thermodynamic self-organization are observed as nonequilibrium phase transitions in the form of violations of scale invariance in Figures 5 and 6 at the $d$ scale up to 45 pixels.

Based on the fractal analysis of the images, it can be concluded that soot particles act as centers with a high energy potential during the modification of cement composite. Polydispersity clusters are formed around these centers, consisting of various more stable and energetically advantageous hydration products from the point of view of crystallization under these conditions. It is possible to form a cluster network under the condition of a uniform distribution of such soot particles in the hardening cement matrix. Stochastic fractals act as a self-similar unit in this cluster network.

\section{Conclusions}

Studies of physical and mechanical properties of the control (additive-free) and modified compositions have shownthat the compressive strength of the control composition is $20.8 \mathrm{MPa}$, and the tensile strength in bending is $4.26 \mathrm{MPa}$. The compressive strength of the modified sample with $0.02 \%$ of soot is $26.9 \mathrm{MPa}$, the tensile strength in bending is 5.2 $\mathrm{MPa}$. The results of X-ray phase analysis and differential thermal analysis showthat the number of changes in the composition of the modified sample wasinsignificant, despite a significant increase of its strength characteristics. It can be assumed that the effect of the additive on the conditions of structure formation did not change the composition of hydration products. The results of scanning electron microscopy show changes in the shape and size of structural elements.

Electronic micrographs with amagnification of 20,000 times were used for fractal analysis of microstructures of the control and soot-modified cement composites. Soot with aparticle size less than $80 \mathrm{~nm}$ and with aspecific surface area of $65-100 \mathrm{~m}^{2} / \mathrm{g}$ was used 
as a modifier. The calculation of the multifractal parameters was performed on the basis of parametrization of electron microscopic images of microstructures using acomputer program. The fractal analysis of the images revealed a change in the relative organization of the system, which justified the nature of the change of mechanical properties of the modified material relative to the additive-free systemfrom the perspectiveof self-organization.

Based on the fractal analysis of the images it can be concluded that soot particles acted as centers with a high energy potential during the modification of the cement composite. Modification of composition with dispersed soot led to a change in the configuration entropy of the mixture $\Delta S^{*}$ due to the relationship between entropy and the measure of ordering of the microstructure by scale invariance. It can be argued that there is a direct and inverse relationship when controlling the structural state through modification.

Polydispersity clusters are formed around these centers, consisting of various more stable and energetically advantageous hydration products from the point of view of crystallization under these conditions. It is possible to form a cluster network under the condition of a uniform distribution of such soot particles in the hardening cement matrix. Stochastic fractals act as a self-similar unit in this cluster network.

Author Contributions: Conceptualization, G.Y. and V.S.; Data curation, I.P., V.B. and O.S.; Formal analysis, V.B. and O.S.; Investigation, I.P.; Methodology, G.Y. and V.S.; Software, V.B. and V.S.; Supervision, I.P.; Validation, V.B.; Visualization, O.S.; Writing-review \& editing, G.Y., I.P., V.S. and O.S. All authors have read and agreed to the published version of the manuscript.

Funding: This research received no external funding.

Institutional Review Board Statement: 2021-04-06c-8 from 20 April 2021 Saint-Petersburg Mining University.

Informed Consent Statement: Informed consent was obtained from all subjects involved in the study.

Data Availability Statement: Data is contained within the article.

Conflicts of Interest: The authors declare no conflict of interest.

\section{References}

1. Kim, G.M.; Nam, I.W.; Yang, B.; Yoon, H.N.; Lee, H.K.; Park, S. Carbon nanotube (CNT) incorporated cementitious composites for functional construction materials: The state of the art. Compos. Struct. 2019, 227, 111244. [CrossRef]

2. Li, Y.; Huang, X.; Zeng, L.; Li, R.; Tian, H.; Fu, X.; Zhong, W.H. A review of the electrical and mechanical properties of carbon nanofiller-reinforced polymer composites. J. Mater. Sci. 2019, 54, 1036-1076.

3. Lee, G.C.; Kim, Y.; Seo, S.Y.; Yun, H.D.; Hong, S. Sulfuric Acid Resistance of CNT-Cementitious Composites. Appl. Sci. 2021, 11, 2226. [CrossRef]

4. Szelag, M. Mechano-physical properties and microstructure of carbon nanotube reinforced cement paste after thermal load. Nanomaterials 2017, 7, 267. [CrossRef]

5. Huang, T.; Li, J.L.; Yang, J.H.; Zhang, N.; Wang, Y.; Zhou, Z.W. Carbon nanotubes induced microstructure and property changes of polycarbonate/poly (butylene terephthalate) blend. Compos. Part B Eng. 2018, 133, 177-184. [CrossRef]

6. Tragazikis, I.K.; Kordatou, T.Z.; Exarchos, D.A.; Dalla, P.T.; Matikas, T.E. Monitoring the Hydration Process in Carbon Nanotube Reinforced Cement-Based Composites Using Nonlinear Elastic Waves. Appl. Sci. 2021, 11, 1720. [CrossRef]

7. Zhang, J.; Tan, H.; He, X.; Zhao, R.; Yang, J.; Su, Y. Nano particles prepared from hardened cement paste by wet grinding and its utilization as an accelerator in Portland cement. J. Clean. Prod. 2020, 283, 124632. [CrossRef]

8. Foldyna, J.; Foldyna, V.; Zeleňák, M. Dispersion of carbon nanotubes for application in cement composites. Procedia Eng. 2016, 149, 94-99. [CrossRef]

9. Han, B.; Yu, X.; Ou, J. Multifunctional and smart carbon nanotube reinforced cement-based materials. In Nanotechnology in Civil Infrastructure; Springer: Berlin/Heidelberg, Germany, 2011; pp. 1-47.

10. Smirnova, O.M. Technology of Increase of Nanoscale Pores Volume in Protective Cement Matrix. Int. J. Civ. Eng. Technol. 2018, 9, 1991-2000.

11. Fedorova, G.D.; Alexandrov, G.N.; Yakovlev, G.I.; Polyanskikh, I.S.; Pudov, I.A. Fine Grain Portland Cement Concrete with Complex Nanodisperse Admixture for Structure Rehabilitating. Adv. Mater. Res. 2015, 1122, 105-110. [CrossRef]

12. Pukharenko, Y.; Staroverov, V.; Ryzhov, D. Nanomodified concrete mixes for form-free moulding. Mater. Today Proc. 2019, 19, 2189-2192. [CrossRef]

13. Konsta-Gdoutos, M.S.; Metaxa, Z.S.; Shah, S.P. Highly dispersed carbon nanotube reinforced cement based materials. Cem. Concr. Res. 2010, 40, 1052-1059. [CrossRef] 
14. Wang, J.; Liu, M.; Wang, Y.; Zhou, Z.; Xu, D.; Du, P.; Cheng, X. Synergistic effects of nano-silica and fly ash on properties of cement-based composites. Constr. Build. Mater. 2020, 262, 120737. [CrossRef]

15. Niu, L.; Xu, J.; Yang, W.; Ma, J.; Zhao, J.; Kang, C.; Su, J. Study on the Synergetic Fire-Retardant Effect of Nano-Sb2O3 in PBT Matrix. Materials 2018, 11, 1060. [CrossRef] [PubMed]

16. Pundienè, I.; Pranckevičienè, J.; Kligys, M.; Kizinievič, O. The synergetic interaction of chemical admixtures on the properties of eco-friendly lightweight concrete from industrial technogenic waste. Constr. Build. Mater. 2020, 256, 119461. [CrossRef]

17. Li, D.; Chen, B.; Chen, X.; Fu, B.; Wei, H.; Xiang, X. Synergetic effect of superabsorbent polymer (SAP) and crystalline admixture (CA) on mortar macro-crack healing. Constr. Build. Mater. 2020, 247, 118521. [CrossRef]

18. Liu, B.; Shi, J.; Liang, H.; Jiang, J.; Yang, Y.; He, Z. Synergistic enhancement of mechanical property of the high replacement low-calcium ultrafine fly ash blended cement paste by multiple chemical activators. J. Build. Eng. 2020, 32, 101520. [CrossRef]

19. Mikhailov, A.V.; Garmaev, O.Z.; Fedorov, A.S. The relationship between fractal properties and active porosity of peat compositions. In Key Engineering Materials; Trans Tech Publications Ltd.: Stafa-Zurich, Switzerland, 2020; Volume 836, pp. 58-62.

20. Vasilenko, T.; Islamov, A.; Kirillov, A.; Doroshkevich, A.; Doroshkevich, N. Investigation of Tectonically Disturbed Zones of Coal Seams of the Kuznetsk Coal Basin Using SANS. J. Surf. Investig. X-ray Synchrotron Neutron Technol. 2020, 14, S235-S241.

21. Yang, J.; She, W.; Zuo, W.; Zhang, Q. Rational application of nano-SiO2 in cement paste incorporated with silane: Counterbalancing and synergistic effects. Cem. Concr. Compos. 2021, 118, 103959. [CrossRef]

22. Wang, H.; Hou, P.; Li, Q.; Adu-Amankwah, S.; Chen, H.; Xie, N.; Zhao, P.; Huang, Y.; Wang, S.; Cheng, X. Synergistic effects of supplementary cementitious materials in limestone and calcined clay-replaced slag cement. Constr. Build. Mater. 2021, $282,122648$. [CrossRef]

23. Güler, Ö.; Cacim, N.N.; Evin, E.; Yahia, I.S. The synergistic effect of CNTs-polymeric surfactant on the properties of concrete nanocomposites: Comparative study. J. Compos. Mater. 2020, 55. [CrossRef]

24. Ghadikolaee, M.R.; Korayem, A.H.; Sharif, A.; Liu, Y.M. The halloysite nanotube effects on workability, mechanical properties, permeability and microstructure of cementitious mortar. Constr. Build. Mater. 2020, 267, 120873. [CrossRef]

25. Da, Y.; He, T.; Shi, C.; Wang, M.; Feng, Y. Studies on the formation and hydration of tricalcium silicate doped with CaF2 and TiO2. Constr. Build. Mater. 2021, 266, 121128. [CrossRef]

26. He, T.; Yang, R.; Guo, X.; Xu, R.; Da, Y.; Fan, X. Effects of liquid accelerators on carbonation properties of C3A and C3S hydration products. Adv. Cem. Res. 2020. [CrossRef]

27. Pashkevich, M.A.; Bech, J.; Matveeva, V.A.; Alekseenko, A.V. Biogeochemical assessment of soils and plants in industrial, residential and recreational areas of Saint Petersburg. J. Min. Inst. 2020, 241, 125-130. [CrossRef]

28. Ochkurov, V.I.; Vilenskii, M.Y. Comparative evaluation of the saving of binder with fine ground slag. In IOP Conference Series: Materials Science and Engineering; IOP Publishing: Bristol, UK, 2019; Volume 666, p. 012026.

29. Klyuev, S.V.; Klyuev, A.V.; Vatin, N.I. Fiber concrete for the construction industry. Mag. Civ. Eng. 2018, 84, 41-47.

30. Flores-Vivian, I.; Pradoto, R.G.; Moini, M.; Kozhukhova, M.; Potapov, V.; Sobolev, K. The effect of SiO2 nanoparticles derived from hydrothermal solutions on the performance of Portland cement based materials. Front. Struct. Civ. Eng. 2017, 11, 436-445. [CrossRef]

31. Habbaba, A.; Zouaoui, N.; Plank, J. Synergistic and Antagonistic Effect of SO4 2-on Dispersing Power of Polycarboxylate. ACI Mater. J. 2013, 110, 641-645.

32. Sobolev, K.; Flores-Vivian, I.; Pradoto, R.G.; Kozhukhova, M.; Potapov, V. The effect of natural SiO2 nanoparticles on the performance of Portland cement based materials. Spec. Publ. 2018, 326, 14.1-14.10.

33. Silva, B.; Pinto, A.P.F.; Gomes, A.; Candeias, A. Effect of Air-entraining and Water-repellent Admixtures and of Their Dosage on the Performance of Lime Mortars. Int. J. Archit. Herit. 2020, 1-15. [CrossRef]

34. Tan, H.; Li, M.; He, X.; Su, Y.; Yang, J.; Zhao, H. Effect of wet grinded lithium slag on compressive strength and hydration of sulphoaluminate cement system. Constr. Build. Mater. 2021, 267, 120465. [CrossRef]

35. Wang, J.; Ma, B.; Tan, H.; Du, C.; Chu, Z.; Luo, Z.; Wang, P. Hydration and mechanical properties of cement-marble powder system incorporating triisopropanolamine. Constr. Build. Mater. 2021, 266, 121068. [CrossRef]

36. Fernández-Jiménez, A.; Garcia-Lodeiro, I.; Maltseva, O.; Palomo, A. Hydration mechanisms of hybrid cements as a function of the way of addition of chemicals. J. Am. Ceram. Soc. 2019, 102, 427-436. [CrossRef]

37. Krivenko, P.; Gelevera, O.; Kovalchuk, O.; Bumanis, G.; Korjakins, A. Alkali-aggregate reaction in alkali-activated cement concretes. In IOP Conference Series: Materials Science and Engineering; IOP Publishing: Bristol, UK, 2019; Volume 660, p. 012002.

38. Maeva, I.S. Modification of Anhydrite Compositions by Ultra- and Nanodisperse Additives. Ph.D. Thesis, Abstract of the Dissertation for the Degree of Candidate of Technical Sciences, Kazan State University of Architecture and Construction, Kazan, Russia, 2010; 20p.

39. Liu, H.; Sun, S.; Wang, L.; Zhang, Y.; Wang, J.; Luo, G.; Han, L. Microscopic Mechanism of the Macroscopic Mechanical Properties of Cement Modified Subgrade Silty Soil Subjected to Freeze-Thaw Cycles. Appl. Sci. 2020, 10, 2182. [CrossRef]

40. Kalina, L.; Bílek, V.; Novotný, R.; Mončeková, M.; Másilko, J.; Koplík, J. Effect of Na3PO4 on the Hydration Process of AlkaliActivated Blast Furnace Slag. Materials 2016, 9, 395. [CrossRef] [PubMed]

41. Karapetian, K.; Dzhevaga, N. Modern technologies of complex processing of phosphates. ARPN J. Eng. Appl. Sci. 2017, 12, $4588-4594$. 
42. Kazanskaya, L.; Privalov, N.; Privalova, S. Fine ground granulated blast furnace slag for saving quantity of binder. E3S Web Conf. 2019, 110, 01055-01059. [CrossRef]

43. Gorlanov, E.S.; Bazhin, V.Y.; Vlasov, A.A. Electrochemical borating of titanium-containing carbographite materials. Russ. Metall. 2017, 2017, 489-493. [CrossRef]

44. ElDeeb, A.B.; Brichkin, V.N.; Kurtenkov, R.V.; Bormotov, I.S. Extraction of alumina from kaolin by a combination of pyro-and hydro-metallurgical processes. Appl. Clay Sci. 2019, 172, 146-154. [CrossRef]

45. Gao, F.; Tian, W.; Wang, Z.; Wang, F. Effect of diameter of multi-walled carbon nanotubes on mechanical properties and microstructure of the cement-based materials. Constr. Build. Mater. 2020, 260, 120452. [CrossRef]

46. Ivanova, V.S.; Vstovsky, G.V. Mesomechanics of fractal structures in nonlinear conditions. Phys. Mesomech. 1999, $2,19-25$.

47. Lu, Z.; Sha, A.; Wang, W. Permeability evaluation of clay-quartz mixtures based on low-field NMR and fractal analysis. Appl. Sci. 2020, 10, 1585. [CrossRef]

48. Gao, Y.; Jiang, J.; De Schutter, G.; Ye, G.; Sun, W. Fractal and multifractal analysis on pore structure in cement paste. Constr. Build. Mater. 2014, 69, 253-261. [CrossRef]

49. Yang, J.; Huang, J.; He, X.; Su, Y.; Tan, H.; Chen, W.; Wang, X.; Strnadel, B. Segmented fractal pore structure covering nano-and micro-ranges in cementing composites produced with GGBS. Constr. Build. Mater. 2019, 225, 1170-1182. [CrossRef]

50. Li, J.; Wang, F.; Yi, F.; Ma, J.; Lin, Z. Fractal analysis of the fracture evolution of freeze-thaw damage to asphalt concrete. Materials 2019, 12, 2288. [CrossRef] [PubMed]

51. Li, D.; Niu, D.; Fu, Q.; Luo, D. Fractal characteristics of pore structure of hybrid Basalt-Polypropylene fibre-reinforced concrete. Cem. Concr. Compos. 2020, 109, 103555. [CrossRef]

52. Lü, Q.; Qiu, Q.; Zheng, J.; Wang, J.; Zeng, Q. Fractal dimension of concrete incorporating silica fume and its correlations to pore structure, strength and permeability. Constr. Build. Mater. 2019, 228, 116986. [CrossRef]

53. Sun, M.; Zou, C.; Xin, D. Pore structure evolution mechanism of cement mortar containing diatomite subjected to freeze-thaw cycles by multifractal analysis. Cem. Concr. Compos. 2020, 114, 103731. [CrossRef]

54. Khlyupin, A.N.; Dinariev, O.Y. Fractal analysis of the three-dimensional microstructure of porous materials. Zh.T.F. 2015, 85, 17-22.

55. Evelson, L.I.; Nikolaenko, A.N.; Rivonenko, Y.A. Some practical aspects of fractal modeling of the structure of nanocomposite material. Constr. Mater. 2015, 11, 25-27.

56. Yakovlev, G.; Cern, V.; Polyanskikh, I.; Gordina, A.; Pudov, I.; Gumenyuk, A.; Smirnova, O. The Effect of Complex Modification on the Impedance of Cement Matrices. Materials 2021, 14, 557. [CrossRef] [PubMed]

57. Stepanov, V.A.; Belykh, V.V. Program for Comparative Fractal Analysis of Raster Images. Federal Service on Intellectual Property. Patent No. 2016615852, 1 June 2016. 